\title{
List of figures and tables
}

Figures

3.1 How to study the effects of proscription on pre-negotiations page 53

3.2 The effect of proscription on pre-negotiation processes

\section{Tables}

3.1 Reciprocal vilification and de-vilification 56

3.2 Proscription and extreme vilification $\quad 57$

3.3 Extreme (de-)vilification and the 'linguistic ceasefire' 59

$\begin{array}{ll}3.4 \text { Sources of power and (a)symmetry } & 61\end{array}$

3.5 How perceived symmetry can be encouraged 63

$\begin{array}{ll}4.1 \text { Proscription and extreme vilification } & 91\end{array}$ 